\title{
Relationship among Influential Factors of Entrepreneurial Intention: An Associational Study
}

\author{
Omid Yaghmaei ${ }^{1}$, Hananeh Shahteimoori Ardestani ${ }^{1}$, Iman Ghasemi ${ }^{2}$, Shahrzad Baraeinezhad ${ }^{3}$ \& Reza Parsa $^{4}$ \\ ${ }^{1}$ International Business School, Universiti Teknologi Malaysia (UTM), International Campus, Kuala Lumpur, \\ Malaysia \\ ${ }^{2}$ Faculty of Management, Universiti Teknologi Malaysia (UTM), Malaysia \\ ${ }^{3}$ Industrial Management Institute (East Branch), Faculty of Management, Iran \\ ${ }^{4}$ Faculty of Entrepreneurship, University of Tehran, Iran \\ Correspondence: Omid Yaghmaei, International Business School, Universiti Teknologi Malaysia (UTM), \\ International Campus, Kuala Lumpur, Malaysia. E-mail: Oyaghmaei@gmail.com
}

Received: February 7, 2015

Accepted: March 11, 2015

Online Published: August 30, 2015

doi:10.5539/mas.v9n9p114

URL: http://dx.doi.org/10.5539/mas.v9n9p114

\begin{abstract}
Nowadays, entrepreneurship has become an important concept in economic, social, and political aspects of our lives. In addition, research on entrepreneurship and significant factors which influence entrepreneurs' intention has become a topic of interest for scholars in many countries. In the past few years, the number of universities offering entrepreneurship courses have increased dramatically, which indicates the increasing importance of entrepreneurship in social, economic, and political dimensions. This research in entrepreneurship has adopted intention models based on Ajzen's theory of Planned Behavior and aims to find out the relationship among influential factors of entrepreneurial intention (i.e., education, previous experience, attitude, subjective norms, and perceived behavioral control) and investigate their effects on entrepreneurial intention. The study was carried out with postgraduate students and the data was collected from 380 male and female master students in Universiti Teknologi Malaysia (UTM) who were in their final year of study. The results showed that there were statistically positive significant relationships among education, subjective norms, and perceived behavioral control of postgraduate students. However, there was no statistical relationship between education and attitude. The results might be helpful for the governments and university policy makers who try to motivate students to become entrepreneurs.
\end{abstract}

Keywords: entrepreneurial intention, entrepreneurship, previous experience, perceived behavioral control, subjective norms

\section{Introduction}

Entrepreneurship is a concept most connected with job, business creation and economic growth (Gartner, 1989). In 18th century, the vital role of entrepreneurship was noticed by scientists, economists and governments. It was linked with growth and success of country, as well as revolution in economies with new products and methods. Therefore, entrepreneurship was associated with pushing economies forward (Schumpeter, 1912). Entrepreneurship is linked with higher satisfaction of entrepreneur at work, compared with regular employed people (Katz, 2007).

The initial researches of entrepreneurship were focused on the role of personality traits. Personality traits are personality characteristics that make a person unique and differentiable from other individuals. Personality traits are based on traits theory, and early researchers believed that people with certain characteristics are more likely to become an entrepreneur (Gartner, 1989). Some of the key personality characteristics linked to entrepreneurship are risk-taking, innovation, autonomy, and motivation. Based on this theory, an entrepreneur born as an entrepreneur and later acquiring helpful skills lead to become a successful entrepreneur. However, some researchers believed that an individual's experience and background leads to shape him as an entrepreneur. From this point of view, an entrepreneur does not necessarily born one, yet personal experience, education, age, gender, and role models lead him in the path to become an entrepreneur. There are a number of researchers and economists who believed entrepreneurship is a career choice, which cannot be explained by the traditional career 
choice theories (Kolvereid, 1996). Therefore, new career choice models such as Schein $(1990,2006)$ were proposed to more adequately explain entrepreneurial behavior. Schein model links attributes such as personal talent, motives and values to an individual's path of choosing a career. Furthermore, Katz (2003) referred to attributes such as autonomy and creativity as the key career anchors. He also pointed out that career anchors are the result of experience.

The importance of entrepreneurship in developed countries is undeniable. Entrepreneurship is linked to development and creating new jobs. Despite the increasing investment on entrepreneurship activities in developed countries, underdeveloped and developing counterparts are still at the beginning of the way. Malaysia, as a country with plans to become developed in next decade, needs higher investment on entrepreneurship and promotes entrepreneurship activities. However, the number of studies in this field is limited in Malaysia (Ariff \& Abubakar, 2002). Today, Malaysia needs to focus on entrepreneurship education, which is noted as a significant factor for increasing entrepreneurship activities. No research has been conducted on the impact of education and experience on the entrepreneurial intentions of post-graduate students in Malaysia. This study attempts to cover this gap in local and global area, by investigating the relationship among influential factors of postgraduate students' intentions towards entrepreneurship in Malaysia.

\section{Impact of Entrepreneurship on Economic Growth and Development}

The importance of entrepreneurship as a contributor to economic growth and development goes back to 18th century. Scientists, economists, and researchers have found out that there is a significant correlation between entrepreneurial activities, and welfare and national production rate (Schumpeter, 1912). Entrepreneurs have been defined as innovators, who bring new methods, way of thinking, product, supply, form of organization, or any other new idea related to running a business. Based on this definition, entrepreneurship works as an engine towards economic growth and development. Moreover, based on this definition, entrepreneurship is a path by which certain people who have lower chances of employment, such as minorities, and women can become self-employed and start their own business. Therefore, it can be stated that entrepreneurship leads to opportunity for these groups to enter the social life, and gain access to higher income level and personal development (Katz, 1993). Entrepreneurship has been linked to higher satisfaction as well.

Cooper and Artz (1995) concluded that entrepreneurs who were running their own business stated higher satisfaction than those who were employed by firms and corporations. Moreover, entrepreneurship activities had a massive impact on the developing of the currently developed countries (Beyene, 2002). The main reason behind the dramatic influence of entrepreneurship on economic growth comes from the fact that it is bond with creating new jobs (Kirchhoff \& Greene, 1995). For instance, in a study conducted by Birch (1997) on a small business in the U.S., it was found that these businesses were responsible for more than 80 percent of the new jobs on the same year.

In recent years, due to the importance of entrepreneurship which is a powerful tool towards economic development, developing countries have started to include entrepreneurial activities in their agenda. This level of importance leads to increase in the number of countries focusing on entrepreneurship; however, there is a key factor unknown yet. Why do some people seek to become entrepreneurs while others do not? This unsolved nature comes from the ambiguity of entrepreneurship roots, as well as the complexity in the methods and approaches taken.

Entrepreneurship is a complex concept, which has been defined differently by different researchers. While some researchers such as Gartner (1989) define it as creating new business, others such as Bygrave (2007) look at it through a process that leads to higher development. Moreover, Krueger (1993) defines entrepreneurship as seeking opportunity despite the current available resources. In fact, there is a conflict among researchers whether entrepreneurship should be used merely for new firms, or it can be used for already existing ones, which go through acquisition (Woo, Cooper, \& Dunkelberg, 1991).

\section{Methodology}

This study uses Theory of Planned Behavior (TPB) introduced by Ajzen (1991), as the theoretical framework, and tests the entrepreneurial intentions of postgraduate students in Malaysia by using structural equation modeling. A sample of 380 postgraduate students in Universiti Teknologi Malaysia (UTM) was randomly selected. A survey questionnaire was used as the data collection tool. This study was quantitative in nature and SPSS software was used for data analysis.

\subsection{Research Hypotheses}

Based on the research objectives, the following research hypotheses were tested: 
- H1: The greater the attitudes toward entrepreneurship, the higher are the entrepreneurial intensions of postgraduate students.

- H2: The greater the subjective norms regarding entrepreneurship, the higher are the entrepreneurial intensions of postgraduate students.

- H3: The greater the perceived behavioral control toward entrepreneurship, the higher are the entrepreneurial intensions of postgraduate students.

- H4: Entrepreneurship education has a positive impact on the entrepreneurial intensions of postgraduate students.

- H5: Previous experience has a positive impact on the entrepreneurial intensions of postgraduate students.

- H6, H7 \& H8: Education and experience have positive impact on the attitude, subjective norms, and perceived behavioral control of postgraduate students.

\subsection{Research Design}

Attitude, perceived behavioral control, subjective norms, experience, and education factors have been posited to influence entrepreneurial intentions - ones planned to start or own a business (Davidsson, 1995; Shapero \& Sokol, 1982). The main aim of this study was, therefore, to generate and expand knowledge about entrepreneurial intentions of postgraduate students in Malaysia. The aim of the study was to be accomplished by designing this correlation study. Correlation describes, in quantitative terms, the degree to which two or more terms are related (Kasomo, 2006). This study specifically examined the relationship among respondents' attitudes, subjective norms, perceived behavioral control, education, and experience with intention to own a business. The study then sought to find out whether there were significant differences in the attitude, subjective norms, and perceived behavioral control, for respondents with different background characteristics, education, and experience. Figure 1 shows the research framework.

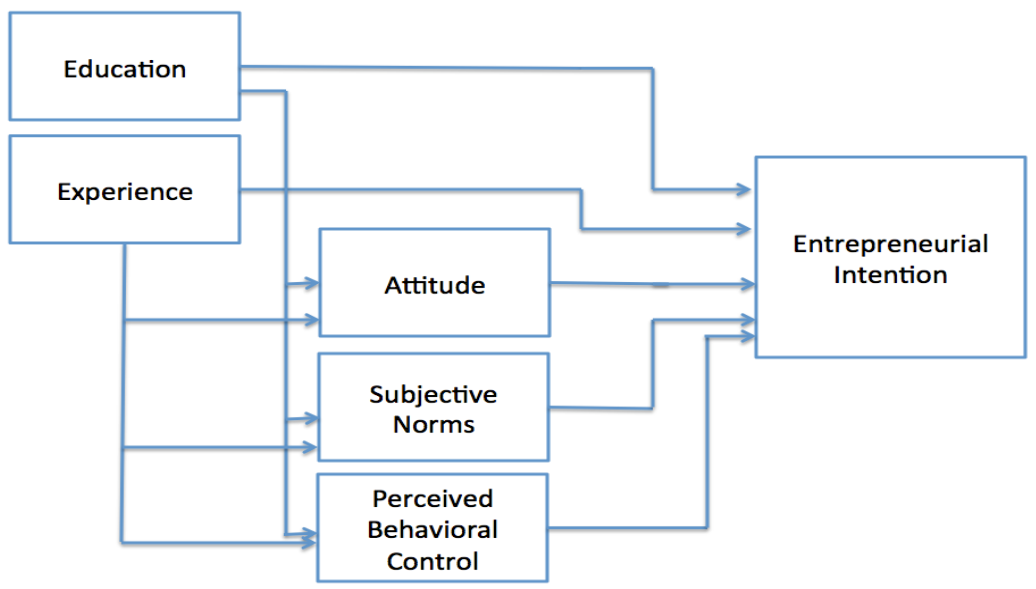

Figure 1. Research Framework

\subsection{Participants}

Following Krejcie and Morgan's (1970) table, data was collected from 380 male and female master students in UTM, Malaysia who were in their final year of study and were considered appropriate for a decision in entrepreneurship. Students in their final year were considered appropriate for a decision in entrepreneurship because according to Shapero and Oskol (1982), entrepreneurship is often preceded by a displacement or precipitating event that triggers action.

\subsection{Pilot Study}

The purpose of pilot testing is to ensure clarity and consistency in the interpretation of the research instruments. Pilot testing also provides a check on the feasibility of proposed procedure for coding data, and shows up flaws and ambiguities and yields suggestions for improvement (Kasomo, 2006). Therefore, the developed survey questionnaire was given to 70 master students in UTM. Each participant was asked to enter comments and recommendations on the sections of the questionnaire which they felt revision was required. Typographic and numbering errors, as well as queries regarding the clarity of some items were considered. The comments were 
incorporated in the final version of the questionnaire.

The items of the questionnaire were on a five point Likert-scale, measured from 'strongly disagree' to 'strongly agree'. The researcher adopted a five-item measure of career intention proposed by Shapero (1982), which captures the perception of personal desirability of entrepreneurship. The other scale covered participants' perceptions of social desirability, feasibility of entrepreneurship, and intention itself.

\subsection{Checking Reliability and Validity}

Validity is the best available approximation to the truth of a given proposition, inference or conclusion. It refers to the accuracy of a study, whether a study measures or examines what it claims to measure or examine (Kasomo, 2006). Kothari (2004) noted that confidentiality should be ensured, to safeguard against socially acceptable responses, and respondents should be given freedom to decide which information about themselves they wish to withhold.

In this study, data were collected from postgraduate students in UTM at the final year of their study. These students would have information about entrepreneurial intentions as they are on the verge of joining the labor market, with options for employment or self-employment. The reliability of the survey instrument was confirmed using Cronbach's alpha. The measure ranges between zero and one but what constitutes an acceptable alpha score is subject to debate. Malhotra (2010) and Tull and Hawkins (1993) recommend 0.6 as acceptable, whereas Churchill Jr and Iacobucci (2009) recommended 0.7. A benchmark of 0.7 was used in this study.

The six constructs of attitude, subjective norms, perceived behavioral control, education, experience, and entrepreneurial intention met this threshold as shown in Table 1. The results supported the reliability of the instrument to measure the intended factors.

Table 1. Cronbach's Alpha Scores for Main Constructs

\begin{tabular}{ll}
\hline Construct & Cronbach's Alpha \\
\hline Attitude & 0.7486 \\
Subjective Norms & 0.7043 \\
Perceived Behavioral Control & 0.7506 \\
Education & 0.7051 \\
Experience & 0.7465 \\
Entrepreneurial Intention & 0.8014 \\
\hline
\end{tabular}

For accuracy of the data collected, the researcher let the respondents understand what the research intended to measure. Key concepts including entrepreneurship, entrepreneurial intention, and small business enterprises were explained. It was also made clear that participation was free, one could skip any item he or she did not feel inclined to answer, that there were no preferred responses, and that the responses were confidential. Data were safely stored to safeguard its integrity. To analyze the data, SPSS was used. The analysis was based on the same constructs used to measure entrepreneurial intention in similar researches conducted by Davidsson (1995) and Krueger et al. (2000).

For its validity, this study was therefore carried out with a relevant and appropriate group. The research instrument was reliable, and endeavors were made to get the respondents to give truthful responses. The data analysis was conducted with reputable tools, and the report was directly drawn from the findings. The random sampling also gives the study external validity - the ability to generalize findings to the population from which the sample is drawn.

The data collection was conducted in UTM, Malaysia. The data collection was conducted in June 2014. A total of 380 questionnaires were distributed among the UTM postgraduate students. This was normally scheduled after classes to avoid interruption of the participating students' learning program. Before completion of the questionnaires, the researcher explained the purpose of the study for the participants. The researcher also indicated that there were no preferred responses. The respondents then signed the consent forms. Key concepts including entrepreneurship and small business enterprises were explained to ensure a common understanding of the terms by the researcher and the respondents. Entrepreneurship was explained as creation of a business based on Gartner (1985), but also ownership of small enterprises not necessarily created by the respondent. Small businesses were described to include micro, and informal enterprises including kiosks, and hawking.

To safeguard anonymity and confidentiality of the responses, the researcher collected the questionnaires and the signed consent forms separately. The respondents retained copies of the signed consent-letters for their records. 
The completed questionnaires were well secured against possible interference, damage, or deterioration.

\subsection{Data Analysis}

The data analysis included simple descriptive statistics, correlation, t-test, linear regression analysis, and factor and effect size analysis. Simple descriptive statistics including frequencies and percentages were used to analyze the respondents' background and demographic data. Mean scores and standard deviation were calculated for the Likert-scale items to develop a participant profile. Correlation analysis was performed to establish the strength of the relationships between respondents' perceptions of personal desirability, social desirability, and feasibility of entrepreneurship with entrepreneurial intention. Subsequent to the correlation analysis, ANOVA was used. Linear regression analysis was also used to determine the predictors of entrepreneurial intention among postgraduate students in Malaysia. Moreover, the factor analysis and effect size analysis were used to determine the factors with the largest influence.

\section{Results and Discussion}

\subsection{Inferential Statistics}

To construct the independent and dependent variables, the means of items related to each variable in the questionnaire have been calculated. Table 2 presents some descriptive statistics of the variables. As can be seen, Skewness and Kurtosis values for all research variables are less than 1 . We can therefore accept that the distribution of variables does not differ much from normal distribution and being normal theory about those variables is true.

Table 2. Descriptive statistics of research variables

\begin{tabular}{llllllllll}
\hline & & & & & & \multicolumn{3}{c}{ Skewness } & \multicolumn{3}{c}{ Kurtosis } \\
\cline { 8 - 11 } & N & Min & Max & Mean & SD & Statistic & Std. Error & Statistic & Std. Error \\
\hline Previous Experience & 380 & 0.0 & 2.7 & 1.4 & 0.6 & -0.2 & 0.1 & -0.6 & 0.2 \\
Education & 150 & 1.4 & 4.5 & 3.2 & 0.6 & -0.7 & 0.2 & 0.3 & 0.4 \\
Attitude & 200 & 1.2 & 5.0 & 3.9 & 0.8 & -0.9 & 0.2 & 0.8 & 0.3 \\
Subjective Norms & 378 & 1.0 & 5.0 & 3.6 & 0.9 & -0.9 & 0.1 & 0.6 & 0.3 \\
Behavioral Control & 376 & 1.3 & 5.0 & 3.8 & 0.7 & -0.7 & 0.1 & 0.7 & 0.3 \\
Entrepreneurial Intention & 295 & 0.9 & 4.4 & 3.0 & 0.7 & -0.5 & 0.1 & 0.0 & 0.3 \\
\hline
\end{tabular}

\subsection{Testing the Hypotheses}

- H1: The greater the attitudes toward entrepreneurship, the higher are the entrepreneurial intensions of postgraduate students.

The Pearson correlation method was selected as a suitable statistical method to analyze the connection between attitude toward entrepreneurship and entrepreneurial intensions of postgraduate students. According to the results of Pearson correlation test presented in Table 3, there was a statistically positive significant relationship between attitude toward entrepreneurship and entrepreneurial intensions of postgraduate students $(r=0.669, \mathrm{p}<0.01)$. The results of the analysis showed that the higher level of attitude toward entrepreneurship is linked to the higher level of entrepreneurial intensions, and vice versa. In other words, students in the category of high attitude toward entrepreneurship displayed more entrepreneurial intensions. Therefore, H01 was rejected while the H1 was accepted.

- H2: The greater the subjective norms regarding entrepreneurship, the higher are the entrepreneurial intensions of postgraduate students.

The Pearson correlation method was selected as a suitable statistical method to analyze the connection between subjective norms regarding entrepreneurship and entrepreneurial intensions of postgraduate students. Based on the results of Pearson correlation test presented in Table 3, there was a statistically positive significant relationship between subjective norms regarding entrepreneurship and entrepreneurial intensions of postgraduate students $(\mathrm{r}=0.496, \mathrm{p}<0.01)$. The results of the analysis indicated that the higher level of subjective norms is connected to the higher level of entrepreneurial intensions, and vice versa. It means that students in the category of high subjective norms displayed more entrepreneurial intensions. So, $\mathrm{H} 02$ was rejected and $\mathrm{H} 2$ was approved. 
- H3: The greater the perceived behavioral control towards entrepreneurship, the higher are the entrepreneurial intensions of postgraduate students.

The Pearson correlation method was selected as a suitable statistical method to analyze the connection between perceived behavioral control towards entrepreneurship and entrepreneurial intensions of postgraduate students. According to the results of Pearson correlation test presented in Table 3, there was a statistically positive significant relationship between perceived behavioral control towards entrepreneurship and entrepreneurial intensions of postgraduate students $(\mathrm{r}=0.560, \mathrm{p}<0.01)$. The results of the analysis demonstrated that the higher level of perceived behavioral control towards entrepreneurship is linked to the higher level of entrepreneurial intensions, and vice versa. In other words, students in the category of high perceived behavioral control towards entrepreneurship displayed more entrepreneurial intensions. Therefore, H03 was rejected and H3 was accepted.

- H4: Entrepreneurship education has a positive impact on the entrepreneurial intensions of postgraduate students.

The Pearson correlation method was selected as a suitable statistical method to analyze the connection between entrepreneurship education and entrepreneurial intensions of postgraduate students. Based on the results of Pearson correlation test presented in Table 3, there was a statistically positive significant relationship between entrepreneurship education and entrepreneurial intensions of postgraduate students $(\mathrm{r}=0.427, \mathrm{p}<0.01)$. The analysis outcomes highlighted that higher level of entrepreneurship education is connected to the higher level of entrepreneurial intensions, and vice versa. It means that students in the category of high entrepreneurship education showed more entrepreneurial intensions. So, H04 was rejected and H4 was accepted.

- H5: Previous experience has a positive impact on the entrepreneurial intensions of postgraduate students.

The Pearson correlation method was selected as a suitable statistical method to analyze the connection between previous experience and entrepreneurial intensions of postgraduate students. Based on the results of Pearson correlation test presented in Table 3, statistically there was a substantial positive relationship between previous experience and entrepreneurial intensions of postgraduate students $(r=0.213, p<0.01)$. The results of the analysis demonstrated that the higher level of previous experience was linked to the higher level of entrepreneurial intensions, and vice versa. In other words, students in the category of high previous experience presented more entrepreneurial intensions. Therefore, H05 was rejected and H5 was approved.

- H6, H7 \& H8: Education and experience have positive impact on the attitude, subjective norms, and perceived behavioral control of postgraduate students.

A suitable statistical method known as Pearson correlation was employed to consider the impact of education and experience on the attitude, subjective norms, and perceived behavioral control of postgraduate students. Based on the findings of Pearson correlation test presented in Table 3, there were statistically positive significant relationships among education and subjective norms, and perceived behavioral control of postgraduate students respectively $(\mathrm{r}=0.500, \mathrm{p}<0.01),(\mathrm{r}=0.551, \mathrm{p}<0.01)$. However, there was no statistical relationship between education and attitude $(\mathrm{r}=0.184, \mathrm{p}>0.05)$. Furthermore, the results indicated that there were statistically positive significant relationships between previous experience and attitude, subjective norms and perceived behavioral control of postgraduate students, respectively $(\mathrm{r}=0.224, \mathrm{p}<0.01),(\mathrm{r}=0.121, \mathrm{p}<0.01)$ and $(\mathrm{r}=0.199, \mathrm{p}<0.01)$. Therefore, by totally ignoring the lack of any relationship between education and attitude, it could be conclude that the higher level of entrepreneurship education and experience were linked to the higher level of attitude, subjective norms, and perceived behavioral control of postgraduate students. It means that students in the category of high education and previous experience displayed more attitude, subjective norms, and perceived behavioral control. So, H06, H07 and H08 were rejected and H6, H7 and H8 were approved.

Table 3. correlation matrix of the research variables

\begin{tabular}{lllllll}
\hline & 1 & 2 & 3 & 4 & 5 & 6 \\
\hline 1- Previous Experience & 1 & & & & & \\
2-Education & $.213^{* *}$ & 1 & & & & \\
3-Attitude & $.224^{* *}$ & .184 & 1 & & & \\
4-Subjective Norms & $.121^{*}$ & $.500^{* *}$ & $.353^{* *}$ & 1 & & \\
5-perceived Behavioral & $.199^{* *}$ & $.551^{* *}$ & $.632^{* *}$ & $.558^{* *}$ & 1 & \\
6-Entrepreneurial & $.189^{* *}$ & $.427^{* *}$ & $.669^{* *}$ & $.496^{* *}$ & $.560^{* *}$ & 1 \\
\hline
\end{tabular}

**. Correlation is significant at the 0.01 level (2-tailed).

*. Correlation is significant at the 0.05 level (2-tailed). 


\section{Discussion and Conclusion}

This study was designed to examine the relationships between the attitude, subjective norms, and perceived behavioral control, with respondent's entrepreneurial intention among postgraduate students in Malaysia, and to determine whether there were any differences in the attitude, subjective norms, and perceived behavioral control of entrepreneurship for students with different education, and background characteristics. This study adopted Ajzen's theory of TBP (Ajzen, 1991). Based on this theory, planned behavior is the best predictor of intention of performing a specific behavior. According to Ajzen's theory of TBP and Shapero and Sokol's (1982) entrepreneur intention framework, 8 Hypotheses were constructed.

Ajzen (1991) believed that three main factors create the intention: (i) attitude, (ii) subjective norms, and (iii) perceived behavioral control. The first three hypotheses in the present research examined the impact of these three factors on entrepreneurial intentions among postgraduate students in Malaysia. Based on the results, there was a statistically positive significant relationship between attitude toward entrepreneurship and entrepreneurial intentions of postgraduate students. It means that the students with higher attitude toward entrepreneurship displayed more entrepreneurial intentions. According to the results, attitude toward entrepreneurship is one of the most important factors (among 8 factors of this study) which influenced entrepreneurial intention among postgraduate students in Malaysia. Moreover, there were statistically positive relationships among subjective norms regarding entrepreneurship, perceived behavioral control, entrepreneurship education, previous experience and entrepreneurial intentions of postgraduate students. According to the results, these factors influenced entrepreneurial intentions of postgraduate students in Malaysia.

Most of the previous studies have shown that students with work experience have higher intentions to be entrepreneurs. For instance, Vesper (1980) believed that the people with higher work experience are more successful in their second or third businesses. In addition, Brockhaus and Nord (1979) stated that people with higher experience and knowledge have higher chance to become entrepreneurs.

The obtained results showed that there were a statistically positive significant relationship among education, subjective norms, and perceived behavioral control of postgraduate students. However, there was no statistical relationship between education and attitude. Generally, it can be concluded that the higher level of entrepreneurship education and experience are linked to the higher level attitude, subjective norms, and perceived behavioral control of postgraduate students.

\section{References}

Ajzen, I. (1991). The theory of planned behavior. Organizational Behavior and Human Decision Processes, 50(2), 179-211.

Ariff, M., \& Abubakar, S. Y. (2002). Strengthening entrepreneurship in Malaysia. Malaysian Economic Outlook: 1st Quarter 2002 Update, 1-22.

Beyene, A. (2002). Enhancing the competitiveness and productivity of small and medium scale enterprises (SMEs) in Africa: An analysis of Differential Roles of National Governments Through Improved Support Services. Africa Development, 27(3), 130-156.

Birch, D. (1987). Job creation in America: How our smallest companies put the most people to work. University of Illinois at Urbana-Champaign's Academy for Entrepreneurial Leadership Historical Research Reference in Entrepreneurship.

Brockhaus, R. H., \& Nord, W. R. (1979). An Exploration of Factors Affecting the Entrepreneurial Decision: Personal Characteristic vs. Environmental Conditions. Paper presented at the Academy of Management Proceedings.

Bygrave, W. D. (2007). The entrepreneurship paradigm (I) revisited. Handbook of qualitative research methods in entrepreneurship, 17-48.

Churchill Jr, G. A., \& Iacobucci, D. (2009). Marketing research: methodological foundations: Cengage Learning.

Cooper, A. C., \& Artz, K. W. (1995). Determinants of satisfaction for entrepreneurs. Journal of Business Venturing, 10(6), 439-457.

Davidsson, P. (1995). Determinants of entrepreneurial intentions.

Gartner, W. (1989). Who is an Entrepreneur? Is the Wrong Question. Entrepreneurship Theory and Practice, 47-68.

Gartner, W. B. (1985). A conceptual framework for describing the phenomenon of new venture creation. 
Academy of management review, 10(4), 696-706.

Gay, L. R., \& Diehl, P. (1992). Research methods for business and management: Macmillan Coll Div.

Goedhuys, M., \& Sleuwaegen, L. (2000). Entrepreneurship and growth of entrepreneurial firms in Cote d'Ivoire. The Journal of Development Studies, 36(3), 123-145.

Kasomo, D. (2006). Research methods in humanities and education. Egerton: Egerton University.

Katz, J. A. (1993). How satisfied are the self-employed: A secondary analysis approach. Entrepreneurship Theory and Practice, 17, 35-35.

Katz, J. A. (2003). The chronology and intellectual trajectory of American entrepreneurship education: 1876-1999. Journal of Business Venturing, 18(2), 283-300.

Katz, J. A. (2007). Education and Training in Entrepreneurship.

Kirchhoff, B., \& Greene, P. G. (1995). Response to renewed attacks on the small business job creation hypothesis. Frontiers of Entrepreneurship Research, 1-14.

Kolvereid, L. (1996). Organizational employment versus self-employment: reasons for career choice intentions. Entrepreneurship Theory and Practice, 20, 23-32.

Kothari, C. (2004). Research methodology: methods and techniques: New Age International.

Krejcie, R. V., \& Morgan, D. W. (1970). Determining sample size for research activities. Educ Psychol Meas.

Krueger Jr, N. F., Reilly, M. D., \& Carsrud, A. L. (2000). Competing models of entrepreneurial intentions. Journal of Business Venturing, 15(5), 411-432.

Malhotra, N. K. (2010). Marketing research: An applied orientation: Prentice Hall.

Schein, E. H. (1990). Organizational culture. American psychologist, 45(2), 109.

Schein, E. H. (2006). Organizational culture and leadership (Vol. 356): Wiley. com.

Schumpeter, J. A. (1912). The theory of economic development: Cambridge, MA: Harvard University Press.

Shapero, A., \& Sokol, L. (1982). The social dimensions of entrepreneurship. Encyclopedia of entrepreneurship, 72-90.

Tull, D. S., \& Hawkins, D. I. (1993). Marketing research: measurement and method: a text with cases: Macmillan.

Vesper, K. H. (1980). New venture strategies: Prentice-Hall, Englewood Cliffs, NJ.

Woo, C. Y., Cooper, A. C., \& Dunkelberg, W. C. (1991). The development and interpretation of entrepreneurial typologies. Journal of Business Venturing, 6(2), 93-114.

\section{Copyrights}

Copyright for this article is retained by the author(s), with first publication rights granted to the journal.

This is an open-access article distributed under the terms and conditions of the Creative Commons Attribution license (http://creativecommons.org/licenses/by/3.0/). 